\title{
Solving Traffic Congestion Problems and Definition Stress-Strain State of Curvilinear Overpass Module Sector-Ring Slab
}

\author{
Adil Kadyrov, Sabit Amanbayev, Aleksandr Ganyukov, Kyrmyzy Balabekova, Bahyt \\ Kurmasheva
}

\begin{abstract}
In the article we discuss the construction of curvilinear overpass module sector - ring slab. Calculation of constructive elements and studied the stress-strain state of a sector-ring. The purpose is the development of the technique and calculation for the new construction of a curvilinear overpass for reduction of traffic jams. The methods uses are mathematical analysis, method of finite elements, method of finite differences, and analytical method of relocation. The purpose of the study is calculate constructive elements of module sector - ring slab and decrease of traffic jams. Researched the bending state of the sector-ring structurally orthotropic slab of the roadway of the curvilinear module of the combined bridge crossing.

The method finite difference is used to determine the bending stiffness. There were selected cross sections of the supporting elements from the condition of their strength; the rigidity of the slab with the thickness.
\end{abstract}

Keywords : analytical method of relocation, curvilinear overpass, method finite difference, traffic jam.

\section{INTRODUCTION}

One of the most urgent problems of modern cities, which violate the functioning of the entire urban infrastructure, are numerous road congestion (traffic jams), which are caused by insufficient throughput of city streets. Traffic jams are economically unprofitable; it is also an ecological problem. All this significantly complicates the protection of nature and control over emissions of harmful substances into the environment, and also causes such phenomena as the aggressive behavior of drivers on the roads and road accidents.

Revised Manuscript Received on February 05, 2020

* Correspondence Author

Adil Kadyrov, Professor of the Departament Transport, transport equipment and tehnology, Karaganda State Technical University, Karaganda, Kazakhstan .Email: adil.kadyrov@mail.ru

Sabit Amanbayev, Chairman of the union of motorists, Almaty, Kazakhstan. Email: director@kao-a.kz

Aleksandr Ganyukov, Senior Lecturer of the Departament Mechanics, Karaganda State Technical University, Karaganda, Kazakhstan . Email: sgn2002@mail.ru

Bahyt Kurmasheva, Senior Lecturer of the Departament Transport, transport equipment and tehnology of Karaganda State Technical University, Karaganda, Kazakhstan .Email: happiness_b@mail.ru

Kyrmyzy Balabekova*, Senior Lecturer of the Departament Transport, transport equipment and tehnology, L.N.Gumilyov Eurasian National University. Email: 06_03_92@mail.ru.

(C) The Authors. Published by Blue Eyes Intelligence Engineering and Sciences Publication (BEIESP). This is an open access article under the CC BY-NC-ND license (http://creativecommons.org/licenses/by-nc-nd/4.0/)
In transport construction there are quite widely used bridge structures of various design solutions across the busy intersections of city streets, including those that allow, without interference in the traffic flows of various directions, changing the direction of vehicles by $90^{\circ}$ relative to the initial azimuth of movement.

In these cases there are used combined bridge crossings consisting of a combination of orthogonal and curvilinear precast modules in Fig. 1.

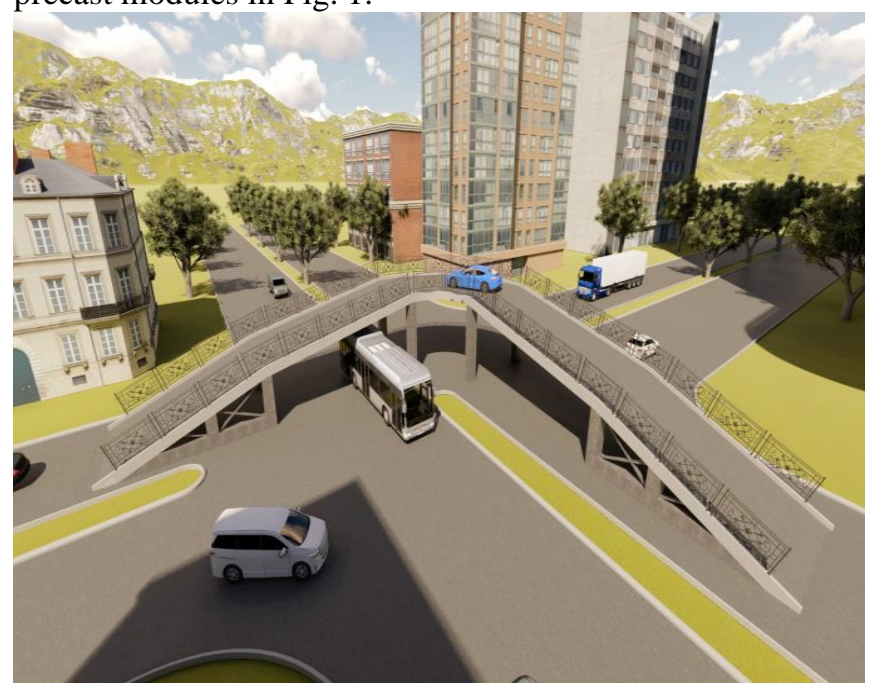

Fig. 1. Curvilinear overpass

The bearing part of the curvilinear module is a structurally orthotropic sector-ring slab with supporting elements in the form of a system of radial and ring structures that can significantly increase the bending rigidity of a thin roadway slab [1].

In connection with the foregoing, it is essential to study the stress-strain state of the bearing elements of a curvilinear module, including its supporting elements, in order to check their strength, rigidity and stability.

\section{METHODOLOGY}

The structural diagram of the roadway slab of the curvilinear module is shown in (Fig. 2), design diagram of a slab with radial-ring mesh (Fig. 3)

and fragment of the radial-ring grid with designation of characteristic nodes (Fig. 4). 


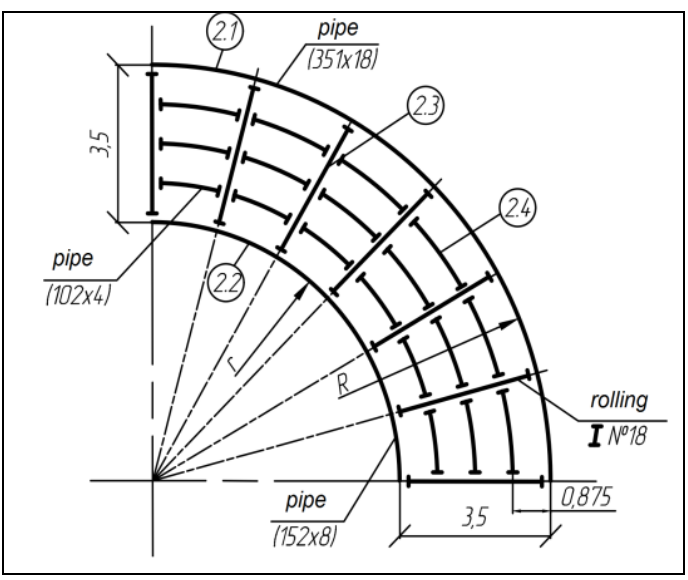

Fig. 2. Structural diagram of the curvilinear module, this is: 2.1 External ring beam (1 pc.)

2.2 Internal ring beam (1 pc.) 2.3 Radial beams (7 pcs.)

2.4 Ring supporting elements (18 pcs.).

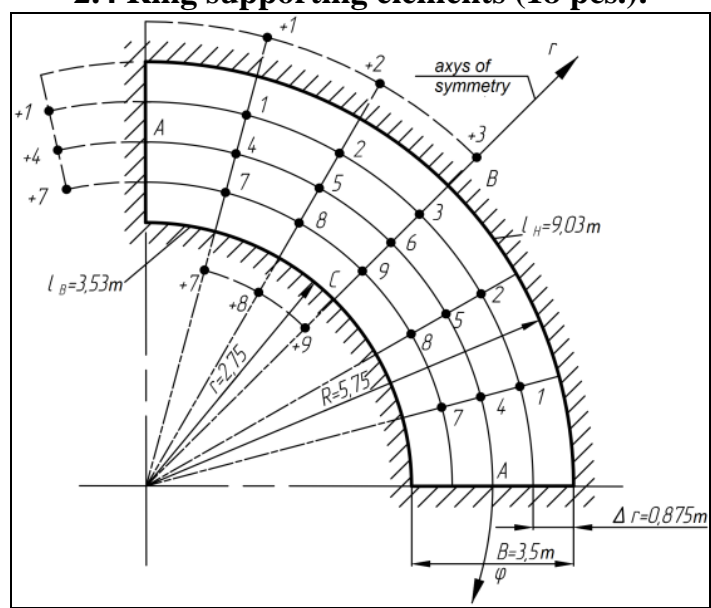

Fig. 3. Design diagram of a slab with radial-ring mesh

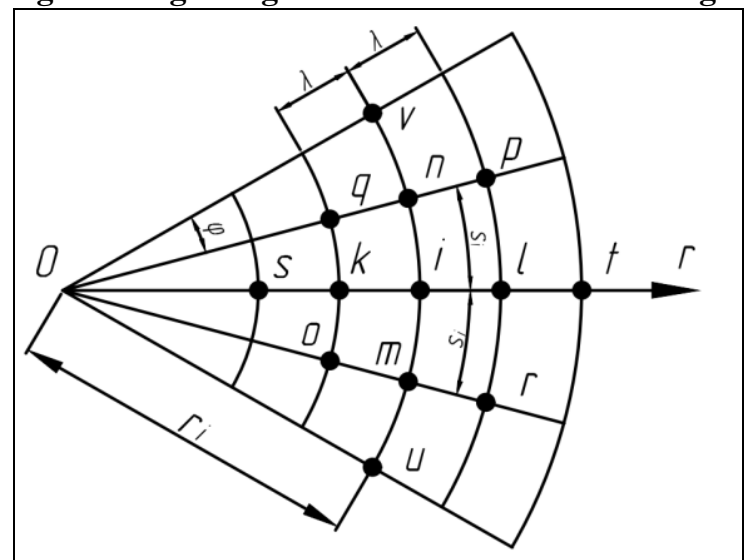

Fig. 4. Fragment of the radial-ring grid with designation of characteristic nodes

\section{MODELING AND ANALYSIS}

The load is evenly distributed over the slab surface from the action of mobile road transport of [taking into account the dynamic impact $\left(\mathrm{k}_{\mathrm{d}}\right)$ and the reliability coefficient for the $\operatorname{load}(\gamma)][1]$ :

$$
\begin{gathered}
g=g_{H} \cdot \gamma \cdot k_{d}=35 \cdot 1,1 \cdot 1,2=46,2 ; \\
g=46,2 \kappa H / M^{2}\left(\mathrm{kN} / \mathrm{m}^{2}\right) .
\end{gathered}
$$

Considering the ring and radial elements of the slab as single-span pinched or hinged at the ends of the beam from the conditions of their load strength $\left(q=g \cdot b_{i}\right) ;\left(b_{i}\right.$ is the truck lane of the $i$-th beam), we select a set of the cross sections that are shown in Figure 1.

Let's study the bending state of the sector-ring structurally orthotropic slab of the roadway of the curvilinear module of the combined bridge crossing (Figure 2).

The initial differential equation through the reduced bending rigidity $\left(D_{\text {nрив }}\right)$ in the radial-ring coordinates has the form $[2,3,4]$ ( $r$ is the radial, $\varphi$ is the angular coordinates):

$$
\frac{\partial^{4} w}{\partial r^{4}}+\frac{2 \partial^{4} w}{\partial r^{2} \partial \varphi^{2}}+\frac{\partial^{4} w}{\partial \varphi^{4}}+\frac{1}{r} \cdot \frac{\partial^{3} w}{\partial r^{3}}=\frac{g}{D_{\text {priv }}},
$$

where $w=w(r, \varphi)$ is the defect function in the radial-ring coordinates; on the surface;

$g$ is the intensity of the load uniformly distributed

$D_{\text {priv }}$ is the reduced bending rigidity (depends on the rigidity parameters of the elements supporting the slab (Figure 2)).

To implement equation (1), we apply the finite difference method (FDM) with a radial-ring grid [5,6], a fragment of which is shown in Figure 3. We apply the grid with the $\left(m_{\varphi} x_{r}=6 x 4\right)$ density (Figure 3$)$; then the number of calculated (inside the contour) grid nodes (taking into account symmetry along the " $r$ " axis will be equal to 9). The grid parameters are as follows [7]:

$$
\Delta r=3,5 / 4=0,875 \mathrm{n} ; \varphi=90^{0} / 6=15^{0}=0,2618 \text { (rad.) }
$$

The reduced bending rigidity $\left(D_{\text {priv }}\right)$ is determined taking into account the presence of the ring and radial elements supporting the slab according to the formula [8]:

$$
D_{\text {прив }}=\frac{E h^{3}}{12\left(1-v^{2}\right)}+\frac{E J_{1 y}}{t_{1}}+\frac{E J_{2 x}}{t_{2}}+\frac{G t^{3}}{12}+\frac{E J_{1 k}}{t_{1} \delta},
$$

where $h=20 \mathrm{~mm}$ is the thickness of the roadway floor slab; $v=0.3$ is the Poisson coefficient for steel;

$E=2 \cdot 10^{5} \mathrm{MPa}$ is the steel elasticity module;

( $t_{1}=B / 4=3,5 / 4=0.875 \mathrm{~m}$ ) is the ring ribs step (Fig. 2);

$\left(t_{2}=l_{H} / 6=9.03 / 6=1.51 \mathrm{~m}\right)$ is the largest step of the radial ribs;

$J_{1 y}=148 \mathrm{sm}^{4}$ is the inertia moment for the ring ribs (element 2.4 in Figure 3);

$J_{2 x}=1290 \mathrm{sm}^{4}$ is the same for the radial ribs (element 2.3);

$J_{1 \kappa}=333.22 \mathrm{sm}^{4}$ is the moment of torsion for the ring ribs; $J_{2 \kappa}=18 \mathrm{sm}^{4}$ is the moment of torsion for the radial ribs.

The coefficient of torsion $\delta$ is calculated by the formula $[2,7]$ :

$$
\delta=1-\frac{t_{1}^{2} J_{1 y}\left(t_{1} J_{2 k}-t_{2} J_{1 k}\right)}{t_{2} J_{2 k}\left(t_{1}^{2} J_{1 y}+t_{2}^{2} J_{1 x}\right)},
$$

For the slab (Figure 3) we have according to (3): $\delta=1,6652$. According to (2) we calculate:

$$
D_{\text {priv }}=27,3 \cdot 10^{5} \mathrm{Nm}=27,3102 \mathrm{kNm}=2,73 \mathrm{MNm} \text {. }
$$

The slag bending rigidity without supporting element (at $h=20 \mathrm{~mm}$ ): 


$$
D=\frac{E h^{3}}{12\left(1-v^{2}\right)}=1,4652 \cdot 10^{5} \mathrm{Nm} ; D_{\text {priv }} / D=18.63,
$$

i.e. the effect of the supporting elements on the bending rigidity of the slab is significant [7]. In the finite differences for the i-th node of the radial-ring grid (Figure 4) equation (1)

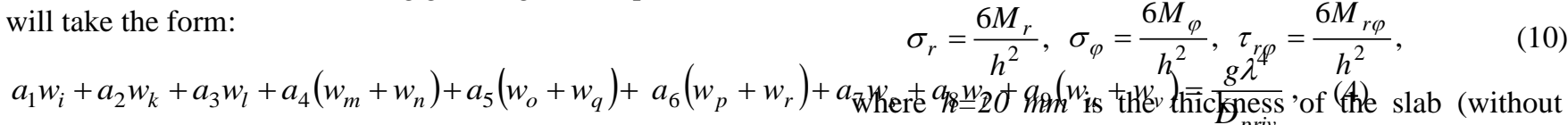
where

$$
\begin{aligned}
& a_{1}=\left(1-\chi_{i}\right)\left(1+\chi_{k}\right)+\left(1-\chi_{i}\right)\left(1-\chi_{l}\right)+2 \alpha_{i}^{2}-4\left(1+\alpha_{i}\right)^{2} ; \\
& a_{2}=-2\left(1-\chi_{i}\right)\left(2+\alpha_{i}+\alpha_{k}\right) ; \quad a_{3}=-2\left(1+\chi_{i}\right)\left(2+\alpha_{i}+\alpha_{l}\right) ; \\
& a_{4}=-4 \alpha_{i}\left(1+\alpha_{i}\right) ; \quad a_{5}=\left(1-\chi_{i}\right)\left(\alpha_{k}+\alpha_{i}\right) ; \\
& a_{6}=\left(1+\chi_{i}\right)\left(\alpha_{l}+\alpha_{i}\right) ; \quad a_{7}=\left(1-\chi_{i}\right)\left(1-\chi_{k}\right) ; \\
& a_{8}=\left(1+\chi_{i}\right)\left(1+\chi_{l}\right) ; \quad a_{9}=\alpha_{i}^{2},
\end{aligned}
$$

where (Figure 3):

$$
\begin{aligned}
& \chi_{i}=\lambda / 2 r_{1} ; \alpha_{i}=\lambda^{2} / s_{i}^{2} ; s_{i}=r_{i} \varphi_{i} ; \\
& g=46,2 \kappa H / \mu^{2} ; D_{\text {nрив }}=27,3 \cdot 10^{2} \kappa H м .
\end{aligned}
$$

Writing the finite-difference equations (4) for the calculated (inside the contour nodes $(i=1,2, \ldots, 9)$ ) (Figure 3 ), we obtain a system of linear algebraic equations (SLAE) of the $9^{\text {th }}$ order, which has the matrix form [9]:

$$
A \cdot \vec{w}=\vec{P},
$$

where $A=\left\|a_{i j}\right\|$ is the square matrix of the $9^{\text {th }}$ order compiled taking into account the radial grid parameters (5) $(i, j=1,2, \ldots, 9)$ (presented in Table 1);

$\vec{w}_{i}=\left\{\left\{w_{1}, w_{1}, \ldots w_{9}\right\} \mid\right.$ is the vector of the grid design nodes (Figure 4);

$$
\vec{P}_{i}=\left|\left\{g_{1} / D_{\text {nрuв }}, g_{2} / D_{\text {npuв }}, \ldots g_{9} / D_{\text {priv }}\right\}\right| \text { is the vector }
$$
considering the external bending load on the slab surface, in our case: $\left(P_{i}=g_{i} \lambda^{4} / D_{\text {priv }}=0,00992\right)=$ const.

Out-of-contour nodes are excluded from the boundary conditions by the slab perimeter, i.e.:

$$
w_{\text {зак }}=w_{\text {nред }} \text {. }
$$

Deflections at the grid nodes on the slab surface are determined by solving equation (6):

$$
\vec{w}=A^{-1} \vec{P},
$$

where $A^{-1}$ is the inverse matrix. By the values of the $\vec{W}$ vector there are calculated the bending and torque moments in the $\mathrm{M}_{r \varphi}$ direction (Figure 4)[8,9]:

$$
\begin{aligned}
& M_{r}=-D_{\text {priv }}\left\{\left(w_{k}-2 w_{i}+w_{l}\right) / \lambda^{2}+v\left[1 / r_{i}\left(w_{l}-w_{k}\right) / 2 \lambda+\right.\right. \\
& \left.+1 / r_{i}^{2}\left(w_{m}-2 w_{i}+w_{n}\right) / \varphi^{2}\right\} \\
& M_{\varphi}=-D_{\text {priv }}\left[1 / r_{i}\left(w_{l}-w_{k}\right) / 2 \lambda+1 / r_{i}^{2}\left(w_{m}-2 w_{i}+w_{n}\right) / \varphi^{2}+\right. \\
& \left.\quad+v\left(w_{k}-2 w_{i}+w_{l}\right) / \lambda^{2}\right\} \\
& \left.M_{r \varphi}=(1-v) D_{\text {priv }}\left\{\left(w_{o}+w_{p}\right)-\left(w_{q}+w_{r}\right)\right] / 4 \lambda_{i} s_{i}-\right\}(9) \\
& -1 / r_{i}^{2}\left(w_{n}+w_{m}\right) / 2 \varphi
\end{aligned}
$$

\section{RESULT AND DISCUSSION}

The largest normal stresses at the slab edge fibers are calculated by the formula [5]

$$
\sigma_{r}=\frac{6 M_{r}}{h^{2}}, \sigma_{\varphi}=\frac{6 M_{\varphi}}{h^{2}}, \tau_{r \varphi}=\frac{6 M_{r \varphi}}{h^{2}},
$$
considering the supporting elements).

In Figures 4, 5 there are presented the results of calculations according to the data of Table I.

The roadway slab rigidity is ensured since:

$$
\begin{gathered}
w_{\max }=0,067 \frac{g \cdot \lambda^{4}}{D_{\text {priv }}}=0,00066 \mathrm{~m}=0,66 \mathrm{~mm} l_{p l}=4,0, \\
{\left[\frac{w_{\max }}{l_{p l}}=\frac{0,66}{4 \cdot 10^{3}}=\frac{1}{6060}\right]<\left[\frac{1}{\delta}=\frac{1}{600}\right] \mathrm{m}}
\end{gathered}
$$


Table - I: SLAE elements (5)

\begin{tabular}{|r|l|l|l|l|l|l|l|l|l|l|}
\hline & W1 & W & W3 & W4 & W5 & w6 & W7 & W8 & W9 & $\begin{array}{l}\text { Vector } P \\
\text { (right part) }\end{array}$ \\
\hline 1 & -5.168 & -6.408 & 1.188 & -2.764 & 1.024 & 0 & 0.221 & 0 & 0 & $g \cdot \lambda^{4} / D_{\text {priv }}$ \\
\hline 2 & -5.352 & -4.809 & -6.408 & 0.856 & -2.764 & 1.024 & 0 & 0.221 & 0 & $g \cdot \lambda^{4} / D_{\text {priv }}$ \\
\hline 3 & 2.017 & -11.76 & -5.997 & 0 & 1.880 & -2.764 & 0 & 0 & 0.221 & $g \cdot \lambda^{4} / D_{\text {priv }}$ \\
\hline 4 & -4.741 & 1.549 & 0 & -9.975 & -7.535 & 1.231 & -4.741 & 1.549 & 0 & $g \cdot \lambda^{4} / D_{\text {priv }}$ \\
\hline 5 & 1.243 & -4.741 & 1.549 & -6.049 & -9.537 & -7.535 & 1.243 & -4.741 & 1.549 & $g \cdot \lambda^{4} / D_{\text {priv }}$ \\
\hline 6 & 0 & 2.792 & -4.741 & 2.024 & -13.584 & -10.768 & 0 & 2.792 & -4.471 & $g \cdot \lambda^{4} / D_{\text {priv }}$ \\
\hline 7 & 1.309 & 0 & 0 & -7.375 & 2.608 & 0 & -11.76 & -9.777 & 1.30 & $g \cdot \lambda^{4} / D_{\text {priv }}$ \\
\hline 8 & 0 & 1.309 & 0 & 1.968 & -9.674 & 2.608 & -7.375 & -11.20 & -9.777 & $g \cdot \lambda^{4} / D_{\text {priv }}$ \\
\hline 9 & 0 & 0 & 1.309 & 0 & 4.576 & -9.674 & 2.04 & -17.152 & -12.5 & $g \cdot \lambda^{4} / D_{\text {priv }}$ \\
\hline
\end{tabular}

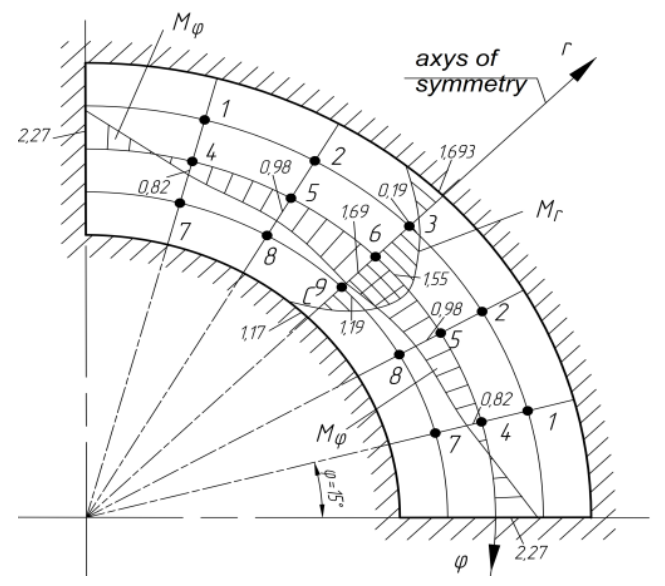

Fig. 4. Deflection diagrams $w_{i}\left(\frac{D_{\text {priv }}}{g \cdot \lambda^{4}}\right), \mathbf{m}$

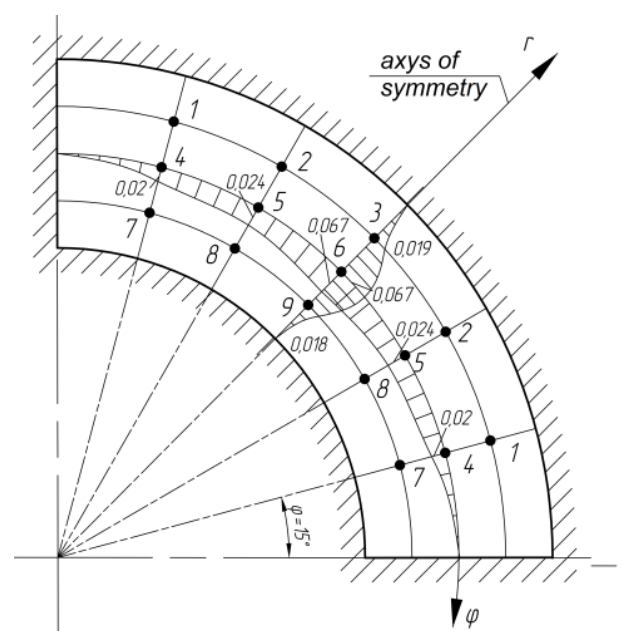

Fig. 5. Diagrams of radial $\left(\mathrm{M}_{\mathrm{ri}}\right)$ and ring $\left(\mathrm{M}_{\varphi \mathrm{i}}\right)$ bending moments $(\mathrm{kNm})$

$w$ is the deflection diagram in the main directions of the radial-ring grid (Figure 4$) ; M_{r}, M_{\varphi}$ are the radial and ring bending moments diagrams (Figure 5) [10,11].

\section{CONCLUSION}

In this paper we studied the stress-strain state of a sector-ring, structurally orthotropic slab using the finite difference method $(\mathrm{M} \varphi)$. A radial-ring grid is used as an approximating grid (Figures 3,4) that optimally fits into the curvilinear outline of the slab.
For such a grid, a $9^{\text {th }}$-order resolving matrix (Table I) was obtained corresponding to the implementation of the FDM for a radial-ring grid; the boundary conditions were provided by rigid support along the contour of the curvilinear slab.

Based on the calculation results, there were built the plots along the main directions of the grid $(r, \varphi)$ : deflections (Figure 3) of bending radial $\left(\mathrm{M}_{\mathrm{r}}\right)$ and ring $\left(\mathrm{M}_{\varphi}\right)$ moments (Figure 5). There were selected cross sections of the supporting elements (Figure 2) from the condition of their strength; the rigidity of the slab with the thickness of $20 \mathrm{~mm}$ was checked (standard rigidity is provided). The theoretical and practical results obtained in this study will find wide application both in scientific research and in the practical design of engineering objects of mechanics in the form of sector-ring, structurally-orthotropic slabs that are widely used in transport and construction. The construction of the mobile overcrossing is proposed, which allows solving the problem of automobile jams on roads.

\section{REFERENCES}

1. Ahmadiev, S.K. Theoretical Foundations design mechanical engineer. Karaganda: KSTU, 2010, pp. 57 - 85.

2. Ahmadiev, S.K. Theory facilities and engineering mechanics. Karaganda: KSTU, 2015, pp. 127 - 193.

3. Darkov, A.B. Structural mechanics, 13th edition. Hardcover: Rare book, 2010, pp. 157 - 286

4. Gordeev, V.N. Loadings and impacts on buildings and constructions. M:Moscow, 2007, pp. 384 - 395.

5. Gordeev V.N., Perelmuter A.V. Loads and impacts on buildings and structures. Moscow: ACB Pub., 2009, 528p.

6. Balabekova, K. G. and Kadyrov, A. S., Research work mobile overpass. In Proceedings of the International scientific-practical conference 'Integration of science, education and production basis for the implementation of the Plan of Nation: selected papers' (ed. Gazaliev A. M.), Karaganda, Kazakhstan, 10-11 December 2015, KSTU, pp 241-243.

7. Kadyrov A.S., Kadyrova I.A. Basics of scientific research. Karaganda KSTU, 2015. p. 267.

8. Ganyukov A.A., Balabekova K.G. Calculation of the spatial frame of the modular overpass. Karaganda: University Proceedings, 2016, №4. p. 63-68.

9. Kadyrov A.S., Balabekova K.G., Ganyukov A.A., Akhmediyev S.K. The constructive solution and calculation of elements of the unified module of the mobile bridge overcrossing // Transport problems. - The Silesian University of Technology, 2017. - Vol. 12. - P. 59-71.

10. Altintas Y. Manufacturing Automation, Metal Cutting Mechanics, Machine Tool Vibrations, and CNC Design // Cambridge University Press. - 2012. - Vol. 12, №6. - P.13-14. 
11. Tasci L., Kuloglu N. Investigation of a new transition curve // The Baltic Journal of Road and Bridge Engineering. - 2011. - Vol. 6, №.1. - P. 23-29.

12. Ziatdinov R., Yoshida N., Kim T.W. Analytic parametric equations of logaesthetic curves in terms of incomplete gamma functions // Computer Aided Geometric Design. - 2012. - Vol. 29, №.2. - P. 129-140.

13. Chmielewski R., Wolniewicz A. Classification of the modernized DMS-65 folded bridge structure according to STANAG 2021 requirements // Roads and Bridges - Dorogi i Mosty. - 2017. - Vol. 16, № 2. - P. 147-158.

\section{AUTHORS PROFILE}

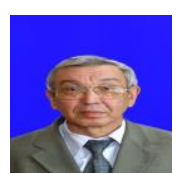

Kadyrov Adil Suratovich,

Professor of the Department "Transport equipment and Logistics Systems", doctor of technical sciences.

Author of more than 200 scientific and methodical works and inventions

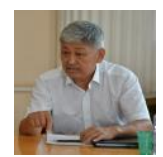

Sabit Shayakhmetovich Amanbayev, General Director, Union of Kazakhstan Transport Workers Association of Legal Entities, Almaty, Kazakhstan, director@kao-a.kz

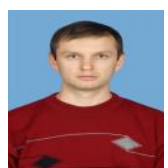

Alexandr Anatolevich Ganyukov.

Senior lecturer of Mechanics department

Email address: a.ganjukov@kstu.kz

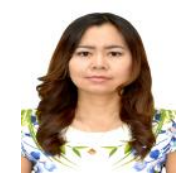

Balabekova Kyrmyzy Ginayatovna, Docent of the Department "Transport, transport equipment and technology".Doctor $\mathrm{PhD}$ in the specialty 6D071300 Transport, transport equipment and technology, 2018, KSTU. Published 30 scientific papers, of which 1 monographs, 2 abstracts of the report, 3 articles - RISC, 1 innovative patents, 7 SIS.

\section{Kurmasheva Bakyt Kuanyshevna,}

Senior Lecturer of the Department "Transport equipment and Logistics Systems". Candidate of Technical Sciences in the specialty 05.05.04 - Road, building and hoisting-and-transport machines, 2008, KSTU. Published 88 scientific papers, of which 4 monographs, 21 abstracts of the report, 3 articles - RISC, 6 innovative patents, 11 SIS; released 8 tutorials. 